\title{
Renato Ivče
}

E-mail: rivce@pfri.hr

\section{Matej Grubiša}

E-mail: matej.grubisa@gmail.com

University of Rijeka, Faculty of Maritime Studies Rijeka, Studentska 2, 51000 Rijeka Darijo Mišković

University of Dubrovnik, Marine Department, Ćira Carića 4, 20000 Dubrovnik

\section{Protection Coatings for the Underwater Part of Ship's Hull}

\begin{abstract}
In this article authors present a general consideration of the underwater part of ship's hull protection by protective coatings, paying particular attention to antifouling paints. Following the presentation of the importance of ship's hull maintenance and protection in order to make navigation safer and to keep the ship in operation for as long as possible, a summary is made of the main types of antifouling products used throughout the history up to the present time. As far back as a thousand years BC, people had developed techniques to protect objects from falling into disrepair and understood the importance of preserving construction materials in order to prolong their useful life and value. Marine industry has been developing day by day and attention is increasingly focused on the safety of ships and crews, as well as on the protection of marine environment. Tin-free self-polishing copolymer (SPC) and foul release technologies are currently applied, in addition to many alternative solutions being suggested. Modern approaches to effective environment-friendly antifouling systems and their performance are highlighted.
\end{abstract}

Keywords: Ship's hull protection, antifouling paints, safety of ships and crews, effective environmentfriendly antifouling coatings

\section{Introduction}

Maritime industry is apparently growing every day. Ship is a very complex and expensive system, and it is of utmost importance that it can perform its function for a longer period of time (up to several decades, depending on the ship type). This fact also entails the need for enhancing ship's hull protection systems. If hull protection from all sources of degradation is carried out in a timely and technically correct manner, it will greatly extend the lifetime of the ship, increase its usability and reduce the cost of maintenance and hull repairs. 
In order to make navigation safer and to keep the ship operable for as long as possible, the maintenance and protection of its hull is of exceptional importance. The hull is considered to be the main structural element of the ship, consisting of the hull and the supporting structure (skeleton) of the ship. These two parts provide the hull's strength and impermeability. It can be concluded that it is obligatory to keep this part of the ship in impeccable condition, as much as possible.

Maritime transport attaches great importance to the maintenance of the ship and its systems. Ship maintenance is considered to be the prevention of defect formation and helps removing them, if they appear. Also, there are actions that extend the lifespan of some systems. In general, we can distinguish two ways of implementing ship maintenance:

- Preventive

- Corrective

By preventive maintenance we consider the maintenance carried out in accordance with pre-prescribed rules and schedules, in order to reduce the possibility of damage, breakdown or shutdown. The most important feature of this way is that it is carried out before the failure occurs. Preventive maintenance includes periodic and control examinations, technical diagnostics and planned repairs.

Corrective maintenance is described as a type of maintenance that is only performed where there is a breakdown or a failure of a particular system or any of its parts. It used to be practiced much more in the past because it was considered cheaper, but the presumption was false because any failure would cause a breakdown and impossibility of usage, wherefore it proved to be very cost-ineffective in the end. Today, corrective maintenance is only applied to auxiliary systems that are not important for navigation. The biggest problem in preserving the underwater part of the ship is corrosion and marine fouling.

Corrosion of the hull is a major problem in the shipping industry. It is a heterogeneous process in which the construction materials are consumed by the chemical reaction of the fluid, causing degradation of metals and inorganic nonmetals. The term corrosion is generally used for the chemical destruction of any solid material. This is a natural process that returns metals to its original state [7]. Corrosion is often associated with the biological and physical decay of materials. It is important to note that erosion and corrosion during navigation are mutually encouraging each other. Erosion removes solid corrosion products that protect the material from further deterioration, corrosion increases surface roughness and converts hard metal into a friable corrosion product. The increase in temperature accelerates corrosion and with sudden changes in temperature layers of corrosion products burst and fall off due to the difference in the coefficient of thermal expansion of the construction material and corrosion products. In the sea, corrosion is accelerated by biological factors such as influence of microorganisms and metabolism products of living beings. In order to solve the problem of corrosion it is necessary to study in detail all factors that influence the formation and development of corrosion. 
There are many micro-organisms and macro-organisms to be found in seawater that live on objects immersed in water. Colonies of such organisms can be found on the surfaces of ships, buoys or other manmade objects at sea. Some of these organisms are limpets, mollusks and seaweed. Ship fouling causes the mass, hull resistance and material stress to increase. An additional problem is seen in the anaerobic corrosion that occurs due to the barrier formed between a surface and the sea water by shell-forming organisms [9]. An acidic microenvironment is formed in which sulfate reducing bacteria are produced that greatly accelerate corrosion. It has been estimated that after only a few months of accumulation of organisms on the hull, the propulsion system requires $45 \%$ more fuel to maintain the same speed as before fouling [5].

In order to prevent the accumulation of fouling, people have designed various methods. They can prevent fouling formation from the first stage (adhesion of bacteria and biofilm formation), but may also affect organisms that are clutched on the biofilm later on. In some antifouling coatings biocides are used to kill the organisms, while in the rest, fouling is prevented by maintaining the ship's hull surface smooth so that organisms cannot attach to the hull [10].

The objective of this article is to cite the ways in which a ship's hull maintenance is carried out, to explain more closely some of them and to introduce the history, the present and future of the maintenance of underwater ship's hull by anti-fouling paints.

\section{Historical overview of ship's hull maintenance}

Since ancient times, there has been a need to protect materials from deterioration caused by external influences. Ancient peoples, who did not know the theory of material deprivation, used certain knowledge about material protection: when they were building the Temple of Solomon in the 950s of our era, its iron elements were covered with asphalt. Between $600 \mathrm{BC}$ and $400 \mathrm{BC}$, Greeks and Romans discovered that except for decoration, paint can also be used to preserve objects. Varnishes mixed with curing oils come to use. Only in the 13th century, the curing oil protective function was discovered in Europe. In the Middle Ages, many paintings, especially those on wood, were protected by lacquering. The resin was made by dissolving the resin in hot oils (seeds of wool, hemp or walnut).

Since the 5th century BC, protection of the underwater part of the ship has been discussed. It was necessary to protect the surface of the hull from fouling, to ensure impermeability and to protect the material from shipworms. From ancient times to the Middle Ages, a mixture of tar, tallow and resin was used to protect the hull. Also, a mixture of arsenic and sulfur in oil, wax and resin mixtures and lead plating of the hull were used. In the antique period, the hull was also protected by metal coatings that reduced fouling and protected against pests. Over time comes the development of ports where ships are cleaned and coated with protective materials. In the 13th century, hull maintenance of the using dry docks has started. 
During the high tide, ships would be brought to the shielded ports, and when the ebb tide occurred, the ship would be stranded and the harbors' entrance would be closed with the door. Throughout the Mediterranean coast, the remains of slipways were found, which would be used to draw the ship out of water using human power. Only at the end of the 17th century, we encounter findings of slipways similar to the ones used today for ship launching. The development of ship docking results in the need for protective coatings.

In the 18th century, the demand for all types of coatings increased. We begin to understand the impact of micro-organisms caught on the hull so the need for antifouling means appears.

One way of maintaining the underwater part of the ship was careening. It is a procedure used to clean the hull and replace damaged hull parts before the dry docks came to use. This method has been used since ancient times up to the thirties of the 20th century. The main reason for the need for careening was the construction of large ships that were too big to be pulled on the coast.

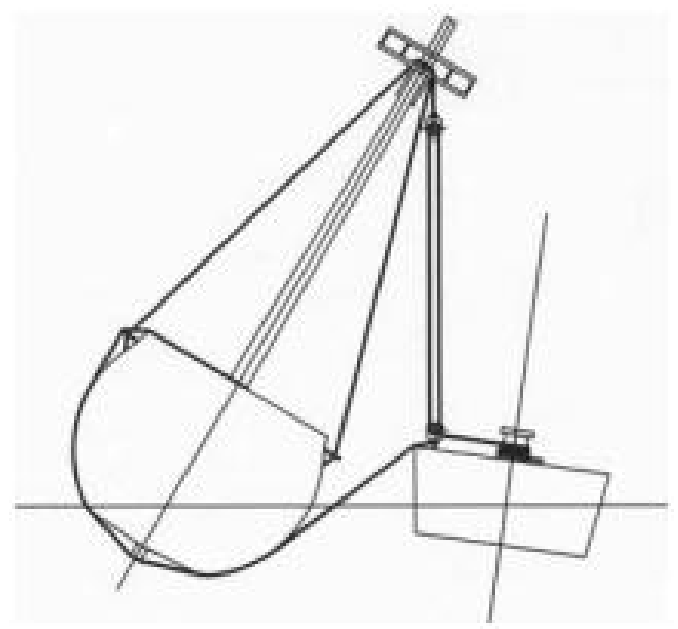

Figure 1 - Careening using a barge Source: [4]

On Figure 1, we see careening using a barge to deliberately list the ship so that a part of its bottom would be exposed for caulking, cleaning, repairing and painting. The barges would be towed to the side of the ship and a thrust pulley with transverse stroke would be mounted. When the rope of the pulley takes a vertical line, the barge would be tilted against the side of the ship. The ship would be kept in an unstable position with the rope tied to the barge and passing under the ships keel using the pulleys. If the rope was tight, the ship was in a stable position, and if it was not, the ship would be in an unstable position [4]. 


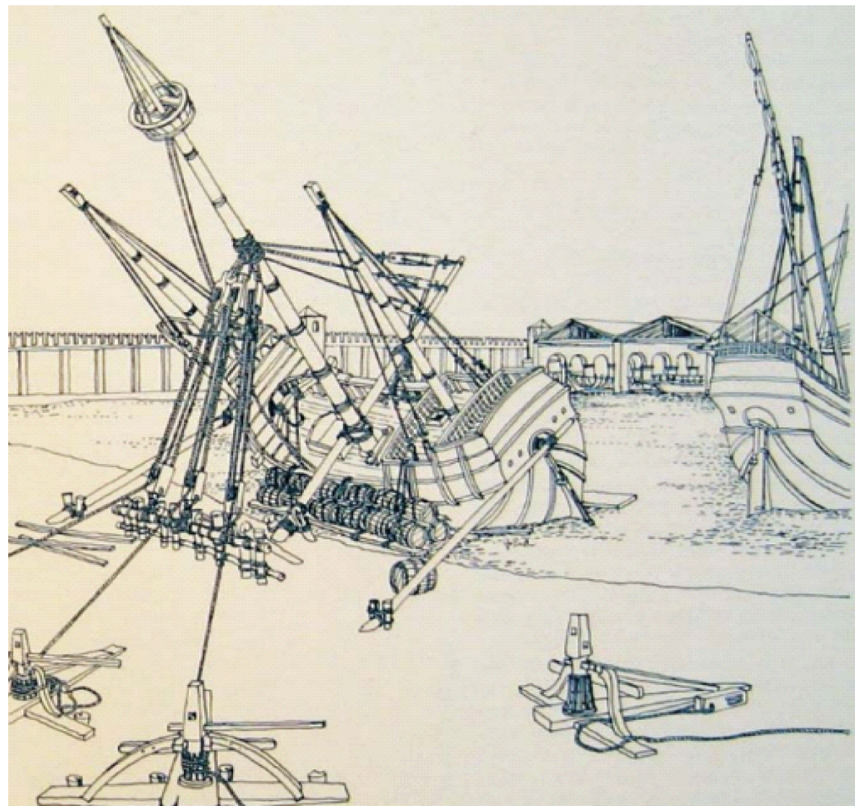

Figure 2 - Careening using shore equipment Source: [4]

Figure 2 shows careening near the coast for the same purpose as mentioned in respect of the preceding figure. Ship was deliberately list using primitive winches and pulleys placed ashore.

The first merchant ship made of iron to cross the Atlantic was built in 1843 and the problem with worms which were boring their way into the hull was upon the shipowner. It is required for the underwater part of this kind of ships, apart from keeping their surface smooth in order to minimize their resistance when the ship is steaming (needed to prevent the attachment of a wide variety of marine organisms), to be efficiently protected against corrosion, primarily by painting. In the mid 19th century, the first antifouling paints were produced and they were based on the idea of dispersing a powerful toxicant in a polymeric binder. The efficacious and cost-effective anti-fouling paints using metallic compounds were developed by the chemicals industry in the middle of 20th century. The most famous among the anti-fouling paints of that time contained the organotin compound tributyltin (TBT). This kind of anti-fouling paints was prohibited after its negative effects on marine organisms had been shown [4]. After that, copper and other metals have been used in anti-fouling paints for many decades. Today, anti-fouling paints can be generally classified in two main categories, as biocide antifouling coatings (often using metallic compounds) and non-biocide antifouling coatings. 


\section{Modern protection of the underwater part of ship's hull}

The maintenance of a ship's hull is a complex and demanding work process dependent on a number of factors that determine both the amount of investment needed and its cost. Nowadays, ship maintenance is rarely done during navigation and is mostly carried out in repair shipyards.

A part of ship's hull is constantly immersed in water and is exposed to the effects of seawater and the organisms that inhabit it. For the purpose of protecting this part of the ship there are protective coatings and the cathodic protection at disposal. In this article protective coatings will be discussed.

Colonies of numerous animal and plant organisms create fouling on structures immersed in seawater, with ships included, thus increasing the resistance and mass of the ship and causing corrosion of the metal surface. Aside from the material degradation, it also leads to a reduction in the ship speed and, as a result, to the fuel consumption increase. In order to reduce the occurrence of fouling, protective coatings are used. Prior to applying the coating, it is necessary to prepare the surface properly by monitoring the environment. It is also important that the coating be properly applied. In addition to fouling prevention, coatings also serve as anticorrosive protection. Surface coatings are used as the most important means of hull protection in anti-corrosive and anti-vegetative point. The basic purpose of the coating is the resistance to external conditions and the prolongation of the life of the material being used. Protective coatings can be metallic and non-metallic and non-metallic can be divided into organic and inorganic.

The shipowner and the shipyard, as well as international organizations, participate in the selection of the coating. Normally, shipowners and shipyards have had long-term cooperation with manufacturers of ship's paint. They have been selecting coatings which will enable the longest possible protection of ship's structure. During the paint application procedure, demanding conditions should be satisfied by the shipyard and all the time the procedure is to be controlled by a competent person from the shipowner's technical department and by the paint manufacturer. It is very important to shipowners that the coating system is durable, easy to maintain, cost-effective and with shortest repair time. Competent authorities such as the Classification Society, Port State Control and Flag State Control take care that the antifouling paint applied on the underwater part of a ship is not harmful for marine organisms. The International Convention on the Control of Harmful Antifouling Systems on Ships was adopted by the International Maritime Organization (IMO) in October 2001. The Convention prohibited the use of harmful organotin in antifouling paint on ships and established a mechanism to prevent the potential use of other harmful substances in the antifouling system.

It is important that coating is applied in accordance with the prescribed requirements and it is necessary to take into account the relative humidity of the air, dew point temperature and surface temperature. The application may be performed in dry weather conditions and at a temperature above $5^{\circ} \mathrm{C}$, unless otherwise specified by the manufacturer [11]. 
Proper and thorough surface preparation prior to coating application will prolong the life of their protective action. In the first place, surface preparation is performed to ensure adhesion of the coating to the ship's hull. The preparation of the surface can be divided into the primary and secondary one. Primary preparation means the treatment of welds, steel lamination and treatment of sharp edges, while the secondary one is performed by removing dirt from the surface and creating surface roughness. Substances that can prevent coating adherence are oil, salt, water condensate, dust, mold, residues of old coating or corrosion. There are three ways for the secondary surface preparation: chemical, thermal and mechanical.

Chemical preparation is performed by applying chemicals, such as acids, alkaline solutions, oxidants, etc. on the surface of the material to eliminate fat, oil and salt. Application can be performed by spraying or immersion. It should be noted here that after the use of alkalis it is necessary to rinse the surface with large quantities of water to remove the newly developed product, which, along with other impurities, prevents the coating to adhere to the surface.

Thermal preparation is used to remove corrosion and corrosion products and is performed by exposing the surface to open flame. The surface temperature should reach $150^{\circ} \mathrm{C}$. Thermal preparation also removes oils, greases, paint residues and moisture from the surface.

The mechanical preparation is performed by grinding and chipping the surface as well as by abrasive blasting and treating with steel brushes. Before applying the coating, it is necessary to make sure that the surface conditions are satisfactory [11].

Protective coatings are applied to the hull in a liquid form and after curing they create a dry protective layer. The applied film must be uniform and free of damage, of a certain thickness and to be in constant contact with the surface. In the preparation for the application, consideration is given to the state of the environment and microclimate, the coating application method and the professionalism of the worker doing the application. The most important factors in applying the coatings are relative humidity, air temperature, dew point and surface temperature [8].

\section{Table 1. Generally accepted microclimate conditions}

\begin{tabular}{|l|l|}
\hline Relative humidity & $\leq 85 \%$ \\
\hline Surface temperature & Dew point $+3^{\circ} \mathrm{C}$ \\
\hline Coating temperature & $15-20{ }^{\circ} \mathrm{C}$ \\
\hline Coating drying temperature & Depending on the coating type \\
\hline
\end{tabular}

Source: Adopted from [3]

Coatings can be applied to the hull by atomization (air assist airless and airless paint sprayers) or manually, with brushes and rollers. Application by atomization is more commonly used because of the higher quality of the applied coating, better surface 
penetration and high productivity. To ensure a sufficient amount of liquid coating, it is necessary to calculate the consumption based on the size of the surface to be coated, the specified coating thickness, and the percentage of dry matter in the coating [3].

The paint consumption calculation is done using these formulas 1, 2, 3 [3]:

Theoretical coverage $\left(\mathrm{m}^{2} / l\right)=\frac{d r y \text { matter percentage }(\%) * 10}{\text { dry film thickness }(\mu \mathrm{m})}$

Theoretical consumption $(l)=\frac{\text { covered surface }\left(m^{2}\right) * \text { dry film thickness }(\mu m)}{\text { dry matter percentage }(\%) * 10}$

In order to calculate practical consumption, it is necessary to take into account certain losses (Loss factor) due to wind as well as paint residues in tanks and hoses (3).

Practical consumption $(l)=\frac{\text { covered surface }\left(m^{2}\right) * \text { dry film thickness }(\mu m)}{10 * \text { dry matter percentage }(\%) * \text { loss factor }}$

It is important to note that today's coatings are used with higher percentages of dry matter in order to use the smallest amount of paint for the same film thickness. Thus, such coatings contain less volatile organic compounds $\left(\mathrm{VOC}^{1} \mathrm{~s}\right)$ that are extremely harmful to the environment.

Coating quality control begins even before the application and is performed during and after the application to the surface. For coating longevity and durability, the surface preparation is of great importance. As already mentioned, with the preparation and coating application done properly, the cost of ship operation is reduced. When assessing the quality level, it is necessary to follow a quality control plan that consists of several parts: surface evaluation, surface preparation, coating application, final inspection and fulfilling the documentation. The coating quality control is done on new ships as well as on repaired ones.

Coating quality control methods can be divided into destructive and nondestructive. In cases of destructive methods, coating is damaged in some places and after the measurement such places have to be repaired. In order to measure the thickness of the coating layers properly, it is necessary to select the correct cutting tool according to the expected thickness of the film. After cutting, values are read on the microscope scale. Adhesion of the coating is essential for the longest possible life of the coating applied to the hull. In general, there are two basic types of adhesion-determining instruments in use: one uses a cutting method to determine the adhesion forces between the surface and the coating, and the other one determines the force within the coating with the separation test [2].

Volatile organic compound 
Non-destructive methods include measuring the thickness of the wet and dry coating layer, the coating cure control and the film porosity testing. The first surface inspection after applying the coating is visual, of course. The examination is performed after drying of each layer. Measuring of dry film is nowadays performed using electronic devices that operate on the principle of magnetic induction. The device probe is first calibrated and leaning at a 90 degree angle on the dry surface. The layer thickness remains on the screen. Detection of all irregularities in the coating is tested using a wet sponge with low voltage. It can be used up to 500 micrometers of film thickness. The sponge is soaked with water and soap is added if needed. The wire from the instrument connects to the metal base. Using the sponge, the operator continually passes over the surface and as soon as the instrument detects a porous part, it generates an audible signal. Damaged surfaces must be first cleaned from paint residues and then coated again. Wet film thickness controls are performed during the application of the coating on the hull. The wet film test is very important in determining the thickness of the film after drying, taking into account the ratio of the dry matter and the solvent to color. The ISO 2808/2007 standard for measuring wet film thickness uses instruments called the wheel and comb that are firmly pressed to the wet coating on the surface and the thickness can be read on the scale marked on the device [2].

\section{Development trend of ship's hull protection}

Maritime industry is developing every day, and attention is increasingly focused on the safety of ships and crews as well as on the prevention of accidental and deliberate pollution of the marine environment. When designing a ship's maintenance system, account is taken of the implementation of the maintenance strategy and of possible risks during navigation. In order to maximize the efficiency, a better connection should be established between ship owners, manufacturers, designers and other participants in the shipping industry.

Unlike in the past, some shipyards apply anticorrosive and anti-vegetative paints using automatic painting plants. By using the considered system, the paint loss during the application is reduced to the minimum and the threat to human health and environment is lower than before.

Paint manufacturers are likely to increase their research efforts toward producing efficient antifouling paints. Today there can be found generally two types of antivegetative paints on the market. One is biocide antifouling paint, containing toxic substances such as metals (mostly copper or zinc) or various organic biocides. Mentioned anti-fouling paints slowly release toxic elements (biocides) when applied on the underwater part of the ships' hull. Biocide from paint slowly dissolves in the surrounding water and at the end it falls on the seabed. It can't be degraded in a natural way (will be deposited in sediment permanently). The second type is the non biocide paint which can usually contain silicone, ceramic or epoxy base which produce slick 
surface. Marine organisms may attach on this surface during ship's stay but when the ship starts steaming, they fall down (minimum sea speed of about 8 knots). Beside the mentioned anti-fouling types, the following systems may be used on various underwater installations: electrolytic system, chemical dosing, ultrasonic system and electro-chlorination.

Ships of gross tonnage (GT) above 400, engaged in the international trade, should be certified as per requirements contained in the International Convention on the Control of Harmful Antifouling Systems on Ships, which prohibits the use of harmful organotin and other harmful substances in antifouling paints. Crafts of 24 meters or more in length but GT less than 400 engaged in the international trade should have a Declaration on Anti-fouling Systems. The Convention has not been applied on crafts up to 24 meters. The growing number of these crafts requires additional attention as well as international and national regulations.

The development of new anti-fouling technologies has been triggered by requirements concerning the reduction of fuel consumption and by more demanding environmental regulations. One of the major challenges faced by the antifouling paint manufactures is the growing number of consumers who require eco-friendly products due to strict environmental regulations. New anti-fouling paints, harmless to marine organisms, have been developed in synergy of science and industry. One of the latest innovations in the anti-fouling technology that has been provided by a marine paint manufacturer is based on the hydrogel technology (a network of advanced polymer chains absorbing high amounts of water to create a water-like boundary layer misguides the fouling organisms into believing that the hull is a liquid surface). Current antifouling technologies for ship hulls based on metals like copper and zinc are trying to be replaced with enzyme-based anti-fouling paints which are proposed as bio-based. Biocide free anti-fouling paints based on a technology which prevents the adhesion of fouling organisms by providing smooth surface on which organisms have difficulty in adhering has also been improved. New paints of this type providing ultra-smooth surface that the fouling organisms fall down from due to the weight of the organism itself or by the water pressure and currents. This paint is superior to the existing ones in application, robustness and drag-reduction effects, all of which help fuel saving and the reduction of ship's exhaust gas emission. Some manufacturers have presented nanotech paint (Teflon based paint) which operates on a self-cleaning principle.

Anti-fouling paint application on crafts up to 24 meters in length should also be adequately supervised. Copper-based and other antifouling paints containing toxic elements should be gradually prohibited and replaced by non-biocide paints. All parties included in the anti-fouling paint application should be well educated. Also additional attention and supervision of anti-fouling paint application, especially in small local ports and marinas, should be carried out by a competent harbor office inspector. Additional researches for new antifouling paints are proposed by the authors in order to establish their real impact on marine environment. 


\section{Conclusion}

Ship's hull is considered to be the main structural element of the ship. Maintenance and protection of the underwater part of ship's hull is very important in order to make navigation safer, to keep the ship in exploitation as long as possible and to reduce ship's fuel consumption. The preservation of the underwater part of the ship from corrosion and marine fouling should be an important task for the shipowner. Fouling of the ship with marine organisms increases the ship's mass, hull resistance and material stress. Also, the problem is the anaerobic corrosion that occurs when the shell-forming organisms make the barrier between the surface and the sea water that leads to corrosion.

Protection of the underwater part of the ship has been mentioned since the 5th century before Christ. Wooden ship's underwater part had to be protected from fouling, to ensure impermeability and also from shipworms. Since ancient times to the Middle Ages there had been many means of hull protection in use; a mixture of tar, tallow and resin, a mixture of arsenic, sulfur in oil, wax and resin mixtures etc. Once the first ship with a metal hull was built, the problem with worms disappeared. Ever since that event, ship's underwater part has required, apart from keeping the surface smooth (to prevent the attachment of a wide variety of marine organisms), an efficient anticorrosive protection by painting.

It is necessary to prepare the surface properly by monitoring the environment prior to applying the coating. For the purpose of the coating longevity and durability, the surface preparation is of great importance. The application of the coating should be performed in accordance with the requirements prescribed by manufactures. Coatings can be applied to the hull by atomization (air assist airless and airless paint sprayers) or manually, with brushes and rollers. Application by atomization is more commonly used because of the higher quality of the applied coating, better surface penetration and high productivity. Coating quality control begins even before the application and is performed during and after the application itself. The methods of coating quality control can be generally divided into destructive and non-destructive.

Today, attention is increasingly focused on the safety of ships and their crews, and also on the protection of marine environment. On the anti-fouling paint market there can be found generally two types of paints. The first type is the biocide antifouling paint, containing toxic substances such as metals (mostly copper or zinc) or various organic biocides. The second type is a non biocide paint that usually contains silicone, ceramic or epoxy base which produce slick surface. The International Convention on the Control of Harmful Antifouling Systems on Ships applies to ships of GT above 400 engaged in the international trade. Crafts of 24 meters or more in length but of GT less than 400 engaged in the international trade should have a Declaration on AntiFouling Systems. Crafts up to 24 meters in length are not covered by this Convention. The new anti-fouling technologies have been developed to meet the requirements of reduction in fuel consumption and improvement in environmental protection. In the 
future, copper-based and other antifouling paints containing toxic elements should be gradually prohibited and replaced by non-biocide paints. Authors propose additional researches for new antifouling paints in order to establish their real impact on marine environment.

\section{References:}

1. Ramesh, T.: Advances in Antifouling Coatings Technology, Coatings World Magazine, September 2018.

2. Kjernsmo, D., Kleven K., Scheie J.: Corrosion protection: Inspector's book of reference, Oslo, 2000.

3. Hempel: Frosio certification course manual, 2007

4. Fabijanić, M.: Karinjenje brodova, Brodogradnja, Vol. 63, No.2, p.184-188., 2012.

5. Magin, Chelsea M., Cooper, Scott P., Brennan, Anthony B.: Non-toxic antifouling strategies. Materials Today, Vol 13., number 4, July 2018.

6. The Organisation for Economic Co-operation and Development (OECD) (2015) Official documents Available from: http://www.oecd.org/ officialdocuments/publicdisplaydocumentpdf, (accessed 08.03.2015.)

7. Esih, I., Dugi, Z.: Tehnologija zaštite od korozije, Školska knjiga, Zagreb 1989

8. Yachtpaint website (2018) Whether to paint depends on the weather. Available from: www. yachtpaint.com/sgp/diy/ask-the-experts/whether-to-paint-depends-on-the-weather.aspx (Accessed 29.06. 2018).

9. Juraga, I., Stojanović, I., Noršić, T. (2007): Zaštita brodskog trupa od korozije i obraštanja, Brodogradnja, vol. 58, no.3., July 2018

10. Zorović, D.: Zaštita materijala, Fakultet za pomorstvo i saobraćaj, Rijeka, 1991-

11. Knifić, Ž., Ivče, R., Komadina, P.: Značenje uporabe zaštitnih premaza u održavanju trupa broda, Pomorski zbornik, vol. 49-50, no. 1., 2015. 